\title{
MULTICULTURALISMO E EDUCAÇÃO MULTICULTURAL: O DEBATE SOBRE AS POLÍTICAS DE IDENTIDADE NA SOCIEDADE AMERICANA
}

\author{
ABU-EL-HAJ, Mônica Farias (Brasil, Ceará, Fortaleza) ${ }^{1 *}$ \\ ${ }^{1}$ Universidade Estadual do Ceará \\ https://orcid.org/0000-0003-3907-5395
}

\section{RESUMO}

O artigo apresenta um panorama bibliográfico em torno do multiculturalismo e da educação multicultural na sociedade americana. Objetiva ampliar o entendimento acerca das controvérsias que envolvem as identidades culturais na atualidade. Inicialmente descreve a luta dos afro-americanos por uma educação que prime pelo reconhecimento e valorização de sua história e identidade cultural. Mostra como essa luta contribuiu para a emergência do movimento dos direitos civis americanos e repercussões na atualidade. Os estudos de James A. Banks constituem as referências mais utilizadas nessa primeira parte. O segundo momento do texto é voltado para o debate teórico sobre os direitos coletivos das minorias nas sociedades ocidentais democráticas. A obra de Will Kymlicka, Multicultural citizenship, é o principal fundamento desse tópico. $\mathrm{Na}$ conclusão, o artigo evidencia a atualidade do debate do multiculturalismo e o papel da educação multicultural para a construção de uma sociedade e de uma escola mais inclusivas.

PALAVRAS-CHAVE: Multiculturalismo. Educação multicultural. Diversidade. Identidade cultural.

\section{MULTICULTURALISM AND MULTICULTURAL EDUCATION: THE DEBATE ON CULTURAL IDENTITIES IN AMERICAN SOCIETY}

\section{ABSTRACT}

The article presents a bibliographic overview of multiculturalism and multicultural education in American society. Its aim is to broaden the understanding of controversies surrounding cultural identities nowadays. Initially, it described the struggle of African Americans for an education that recognized and valued their history and cultural identity. It showed how that struggle contributed to 1960s and 1970s civil rights movement and which continued to be relevant in current educational debates. The James A. Banks studies are the most commonly used references in this first part. The second part focused on theoretical exchanges concerning minorities collective rights in western democracies. The book by Will Kymlicka, Multicultural citizenship, is the main source of this topic. In sum, the article highlighted the current relevance of multicultural debates and the role of multicultural education in promoting social and educational inclusion.

\section{MULTICULTURALISMO Y EDUCACIÓN MULTICULTURAL: LOS DEBATES SOBRE LAS IDENTIDADES CULTURALES EN LA SOCIEDAD AMERICANA} \section{RESUMEN}

El artículo presenta un panorama bibliográfico en torno al multiculturalismo y la educación multicultural en la sociedad americana. Objetiva ampliar el entendimiento acerca de las controversias que involucran las identidades culturales en la actualidad. Inicialmente describe la lucha de los afroamericanos por una educación que prime por el reconocimiento y valorización de su historia e identidad cultural. Muestra cómo esta lucha contribuyó a la emergencia del movimiento de los derechos civiles americanos y repercusiones en la actualidad. Los estudios de James A. Banks constituyen las referencias más utilizadas en esa primera parte. El segundo momento del texto se dirige al debate teórico sobre los derechos colectivos de las minorías en las sociedades occidentales democráticas. La obra de Will Kymlicka, Multicultural citizenship, es el principal fundamento de este tema. En la conclusión, el artículo evidencia la actualidad del debate del multiculturalismo y el papel de la educación multicultural para la construcción de una sociedad y una escuela más inclusivas.

PALABRAS CLAVE: Multiculturalismo. Educación multicultural. Diversidad. Identidad cultural. 


\section{INTRODUÇÃO}

Este artigo apresenta uma revisão de literatura dos debates acadêmicos em torno do multiculturalismo, focando principalmente na evolução e história das ideias dentro da academia e contexto educacional americano. É fruto do contato da autora com os estudos e movimento da educação multicultural nos Estados Unidos durante seu estágio de pós-doutoramento, sobretudo com a atuação e pesquisas da professora Mariana Souto-Manning $(2010,2013)$, docente do Teachers College da Universidade de Columbia, que trabalha com a formação teórica e prática de professores da educação básica na perspectiva da diversidade e inclusão escolar. Ao trazer as origens e debates do multiculturalismo e da educação multicultural no contexto estadunidense, este estudo busca contribuir para o enriquecimento das discussões que envolvem as políticas de identidade no campo educacional brasileiro.

O trabalho levanta a tese de que a produção acadêmica e as agendas de pesquisas sofrem uma influência direta das lutas sociais e mobilizações de intelectuais em prol dos direitos de cidadania, situação que se mostra evidente em relação aos grupos étnico-raciais reprimidos pela cultura dominante. No caso específico americano, o multiculturalismo passou por uma redefinição em duas ondas. Na primeira, centrou-se na temática da assimilação e acomodação dos grupos étnico-raciais à cultura dominante, refletindo os diferentes posicionamentos político-ideológicos envolvidos na defesa e luta das minorias. Nesta, houve uma extensa produção acadêmica, acompanhada de propostas variadas para a organização de currículos escolares e formação de professores.

A ineficácia dessa primeira onda em promover os direitos de cidadania levou ao renascimento do multiculturalismo, durante o apogeu das lutas civis na década de 1960, agora redesignado como "política de identidade". A partir desse momento, a autoafirmação dos direitos culturais como parte integrante e legítima das sociedades contemporâneas passa a determinar as agendas de pesquisas e novas práticas pedagógicas, tanto no que concernem ao desenho dos currículos quanto no que concernem à formação de professores. Essa linha defende que o multiculturalismo promova uma nova dinâmica na autoafirmação de grupos historicamente excluídos, levando a uma ação mais ativa do Estado ante as políticas de identidade e da escola na 
construção de propostas e relações pedagógicas efetivamente abertas e comprometidas com o perfil multicultural das sociedades na contemporaneidade.

Para revelar a complexidade do multiculturalismo, o texto foi dividido em três partes, além desta Introdução. Na primeira depois desta seção, aborda-se a extensa luta dos negros americanos por escolas e uma educação que prime pelo reconhecimento e valorização de sua história e identidade cultural. Mostra como essa luta impulsionou a emergência do movimento dos direitos civis americanos nos anos de 1960 e 1970 e suas repercussões na atualidade. Os estudos de James A. Banks, um dos expressivos teóricos e especialistas da história do movimento da educação multicultural nos Estados Unidos, constituem as referências mais utilizadas nessa seção.

A terceira seção do artigo traz os argumentos e polêmicas que giram em torno das políticas de identidade, voltando-se para o debate teórico dos direitos coletivos das minorias nas sociedades democráticas, o qual é tratado na perspectiva da obra Multicultural citizenship, de Will Kymlicka. $\mathrm{O}$ autor se enquadra entre os teóricos mais citados na literatura acadêmica internacional em defesa das políticas multiculturais (CARTER, 2012; CHRISTMAN, 2014; FULLINWIDER, 2014; LEYDET, 2014; SONG, 2014).

Finalmente a conclusão do texto mostra como educadores e pesquisadores estadunidenses concebem atualmente a educação multicultural e seu papel na perspectiva da inclusão e integração das minorias na sociedade.

\section{A LUTA DOS NEGROS AMERICANOS PELOS DIREITOS CULTURAIS}

A literatura internacional (BANKS, 1993; FULLINWIDER, 2014; SONG, 2014; TAYLOR, 2012) situa as origens do multiculturalismo no movimento dos direitos civis (civil rights) americanos nas décadas de 1960 e 1970, ressaltando o papel que os negros desempenharam tanto para a eliminação das leis segregacionistas quanto para a ampliação das demandas de reconhecimento das identidades culturais e de oportunidades para as demais minorias (imigrantes, populações indígenas, mulheres, etc.). Esse dado se mostra importante, uma vez que a reconstituição do movimento negro nos Estados Unidos nos ajuda a compreender a longínqua história dos conflitos

Educação \& Formação, Fortaleza, v. 4, n. 10, p. 195-213, jan./abr. 2019

DOI: https://doi.org/10.25053/redufor.v4i10.847

http://seer.uece.br/redufor 
étnico-raciais e as distintas visões e interpretações teóricas que foram surgindo e continuam a gravitar em torno da integração das minorias na sociedade.

Convém observar os mexicanos na expansão do estado da Califórnia desde os meados do século XIX, a expressiva leva de imigrantes europeus para as cidades da Costa Leste no final do século XIX e início do século XX, além do crescimento da imigração de latinos e asiáticos no final do século $X X$, que suscitaram igualmente 0 surgimento de ações afirmativas étnico-culturais no país, ainda que neste escrito as atenções se voltem para os movimentos afro-americanos.

Ao reconstituir os acontecimentos que precederam a educação multicultural nos Estados Unidos, Banks (1993) descreve a intermitente luta dos negros, que se inicia já no século XIX, pelo direito à educação e a uma escola que inserisse em seu currículo e livros didáticos a história dos afro-americanos e sua cultura. $\mathrm{O}$ autor exprime o percurso desse movimento permeado e intercalado por duas visões e formas de atuar junto aos processos de acomodação dos negros numa sociedade fortemente marcada pelas discriminações e segregações raciais.

Assim, ora esses movimentos assumiam posições e mobilizações mais radicais - momento em que suas reivindicações pendiam inclusive para saídas separatistas, quando predominava entre os negros a intenção de que seus filhos frequentassem escolas próprias, isoladas dos estabelecimentos de ensino da população branca -, ora assumiam posições e mobilizações mais brandas - quando o peso recaía na ideia de uma convivência harmônica entre negros e brancos, encontrando num modelo de educação intergrupal a saída para os problemas das discriminações e acomodações dos negros na grande sociedade.

Banks (1993) descreve o final do século XIX e as primeiras décadas do século $\mathrm{XX}$ como um período profícuo na trajetória dos movimentos negros, marcado por uma intensa produção de obras sobre a história e a cultura dos afro-americanos, a maioria de autoria de intelectuais negros que pertenciam ao "grupo dos estudos étnicos". Essa vertente do movimento defendia o fortalecimento e empoderamento das comunidades afro-americanas por meio da valorização da identidade negra, a qual se daria pela reconstituição da verdadeira história de seu povo nos Estados Unidos, até então ausente dos currículos e livros escolares, e da riqueza de suas produções materiais e 
manifestações culturais e simbólicas na linguagem, literatura, religião, indumentária, entre outras.

Para defensores dos estudos étnicos, o cultivo de um sentimento de orgulho e pertença racial era algo imprescindível para que os negros desenvolvessem uma atitude de resistência às discriminações e injustiças sofridas na sociedade. Na publicação do livro Mis-education of the negro, em 1933, Carter G. Woodson, um dos expressivos intelectuais de grupo no campo educacional (movimento que contava também com a participação de personagens como W. E. B. DuBois e Charles H. Wesley, entre outros), argumenta que as escolas e as universidades:

[...] estavam deseducando os alunos afro-americanos quando descreviam apenas a civilização europeia e não mencionavam a civilização africana e sua cultura na formação de seus alunos e que essa negligência resultava em danos negativos sobretudo no que se referia à autoestima dos jovens afro-americanos. (BANKS, 1993, p. 12).

Nos anos de 1950, todavia, a crescente oferta e a competição por postos de trabalho e moradia no período pós-guerra - impulsionadas principalmente pelo desenvolvimento da indústria bélica - levaram ao acirramento dos conflitos étnico-raciais nos Estados Unidos. De um lado, o aumento da migração de brancos e negros das zonas rurais para centros urbanos aprofundou os conflitos entre esses dois segmentos nas cidades do Oeste e, de outro, a leva de migração para as cidades do Nordeste dos Estados Unidos elevou a tensão entre brancos e imigrantes mexicanos.

De acordo com Banks (1993), as proporções significativas dos conflitos provocaram um sentimento nacional de preocupação concernente aos problemas inter-raciais e étnicos vividos à época. Nesse momento, surgiu o movimento da educação intergrupal ou intercultural, liderado por educadores e cientistas sociais liberais, a maioria composta por intelectuais brancos que atuavam em universidades e instituições nacionais de prestígio; conforme observa Banks (1993), ao contrário da visão mais pluralista de educação cidadã defendida pelos líderes do grupo dos estudos étnicos, achavam que a assimilação dos negros e imigrantes na cultura e instituições dominantes seria o caminho mais adequado para a sua integração e acomodação.

Enquanto o movimento dos estudos étnicos, que predominou nas primeiras décadas do século $X X$, enfatizava a pertença, o orgulho e o empoderamento da identidade cultural negra como formas de valorizar e fortalecer a autoestima e o 
autorrespeito dos estudantes negros perante a sociedade, o foco do movimento da educação intergrupal era a redução do preconceito e das discriminações étnico-raciais, fundamentada na formação de valores democráticos, nas relações humanas e na harmonia inter-racial.

Banks (1993, p. 16) ressalta que, apesar dos valiosos estudos e publicações nascidos sob os auspícios do movimento da educação intergrupal, a crença de que todas as pessoas seriam tratadas de forma justa e viveriam em harmonia refletia um modo ingênuo de tratar a diversidade, amparada em uma noção de que "[...] somos diferentes, mas semelhantes" - "[...] we are different but the same". Imbuídos do clamor democrático que alimentava o ideário da sociedade estadunidense, dedicaram pouca atenção às questões estruturais que fomentavam os comportamentos racistas e as relações de poder nas instituições sociais, bem como as iniquidades que refletiam a condição de desvantagem dos negros e das demais minorias étnicas na sociedade.

No final dos anos 1950, muitos afro-americanos ligados ao antigo grupo dos estudos étnicos, cansados e desacreditados com a demora e a falta de solução para os guetos e desigualdades raciais, tornam-se os principais protagonistas do movimento dos direitos civis que emergiu no país nos anos 1960 e 1970 (BANKS, 1993, 1999). Nesse momento, a força com que se deu o ressurgimento dos movimentos étnicos que abalaram os Estados Unidos nos anos 1960 e 1970 mostrava que as demandas por direitos civis e sociais tinham atingido também o clamor de outras minorias, a exemplo dos imigrantes e das mulheres. Segundo Kymlicka (2000), assim como os negros, os imigrantes tinham se tornado mais conscientes de seu status como grupo e reivindicavam a legitimidade de expressarem suas distintas identidades e características.

Vale observar que a primeira fase do movimento dos direitos civis, à semelhança do que ocorrera nas primeiras décadas do século com o grupo dos estudos étnicos, foi marcada por um sentimento separatista que refletia tanto a visão de desesperança dos líderes afro-americanos quanto de alguns grupos de imigrantes. Esse é um momento muito importante na história social e política dos Estados Unidos, com suas repercussões posteriormente em outros países e continentes, porque pela primeira vez se questionava, de fato e de direito, o mito da liberdade e igualdade que fundamentava as sociedades democráticas ocidentais e sua capacidade de promover a inclusão e o bem-estar de todos os seus indivíduos. 
Não por acaso, a demanda pela ampliação dos direitos civis, nesse período denominada de "terceira geração dos direitos civis", passou a ser designada de "direitos de filiação cultural" (FULLINWIDER, 2014). No decorrer dos anos 1970, 1980 e 1990, as manifestações e reivindicações levaram progressivamente à implantação de um conjunto de dispositivos legais (leis, projetos, políticas) de combate às discriminações e reconhecimento das identidades culturais dos grupos étnico-raciais (negros, imigrantes e tribos indígenas), estendendo-se, em seguida, às demandas de outras minorias (mulheres, pessoas com necessidades especiais, homossexuais, etc.).

Com o advento do movimento dos direitos civis, duas medidas entrariam em vigor nos Estados Unidos, com repercussões no âmbito internacional: primeiro, o direito de as minorias afirmarem e manifestarem suas identidades culturais. Segundo, o direito de as minorias serem assistidas pelas denominadas "políticas afirmativas". Estas compreendiam tanto a implantação de políticas de cotas em postos de trabalho e em instituições educacionais quanto políticas de fomento, direcionadas ao desenvolvimento de projetos e programas de entidades comunitárias e escolares de apoio às manifestações culturais e religiosas dos grupos minoritários (KYMLICKA, 2000). O movimento dos direitos civis também fomentou a reimpressão de muitas obras valiosas produzidas pelo grupo dos estudos étnicos no início do século, que passaram finalmente a ser introduzidas paulatinamente nos currículos oficiais das escolas.

É dentro desse contexto que Banks $(1993,1999)$ identifica, de fato, a primeira fase do movimento da educação multicultural nos Estados Unidos, quando se constata a ação individual e institucional de estudiosos e ativistas no sentido de inserir as obras, os conceitos e as teorias do grupo dos estudos étnicos no currículo escolar e nos cursos de formação de professores nas instituições de ensino superior (colleges e universidades). A atuação desses ativistas culminou com uma importante mudança, a exigência da implementação de componentes, cursos e programas de educação multicultural nos cursos de formação de professores (BANKS, 1993).

No momento, todavia, em que as discussões teóricas e políticas em torno do multiculturalismo ganham ampla projeção, logo surgem as primeiras contestações a esse novo paradigma e suas políticas, e muitos intelectuais passam a proclamar o seu precoce declínio. As críticas ao multiculturalismo tinham como alvo o peso dado às identidades e à filiação cultural como mecanismos que levariam à integração das 
minorias étnico-raciais nas sociedades democráticas ocidentais. As primeiras contestações vieram dos movimentos feministas, que passaram a denunciar a contradição que residia na defesa das tradições culturais e religiosas de alguns grupos minoritários, quando vistas na perspectiva da luta pela emancipação e libertação das mulheres.

Segundo Gozdecka, Ercan e Kmak (2014), o expressivo aumento dos movimentos feministas nas sociedades urbanas ocidentais e das denúncias relativas à desigualdade de gênero em grupos culturais minoritários na Europa e no Ocidente anglófono era o indicador mais visível da mudança para um período pós-multiculturalista. Além disso, a recessão econômica e o aumento das taxas de desemprego em parte da Europa e posteriormente nos Estados Unidos colocaram os imigrantes mais uma vez no centro das tensões sociais. Por fim, os atentados terroristas na entrada do novo milênio, retratados sobretudo pelas inimagináveis cenas do 11 de setembro, culminaram nas críticas mais duras ao multiculturalismo (TAYLOR, 2012).

Para os críticos do multiculturalismo, as políticas de identidade mais contribuíam para a "guetização" dos imigrantes nas sociedades ocidentais do que para sua integração econômica, social e cultural. Além de acirrarem os confrontos étnico-raciais, as políticas de identidade desviavam o olhar da sociedade para os problemas estruturais que envolviam a acomodação dos grupos minoritários nos países desenvolvidos. Já para os defensores do multiculturalismo, tais contestações não se sustentavam, uma vez que revelavam mais uma vez o fracasso dos estados e sociedades democráticas ocidentais em promover a adequada acomodação das minorias étnico-raciais, preferindo identificar nas políticas de identidade o "bode expiatório" para os problemas econômicos e o aumento dos conflitos sociais (KYMLICKA, 2000; TAYLOR, 2012).

Um dos resultados dessa polêmica em torno do multiculturalismo foi a adoção de novos termos para 0 debate da acomodação das minorias, a exemplo do interculturalismo. Segundo Taylor (2012), em tempos de crise econômica e política, quando as dimensões simbólicas tendem a dar um novo tom às relações entre os grupos sociais, o termo "interculturalismo" soa de modo mais palatável ou conciliatório. A diferença entre os dois conceitos - multiculturalismo e interculturalismo -, conforme explica o autor, reside mais em discussões retóricas do que propriamente em agendas políticas. Enquanto no multiculturalismo a ênfase do prefixo "multi" está na diversidade, a 
do prefixo "inter" resulta na integração (TAYLOR, 2012). Outros autores passaram a defender um "multiculturalismo sem cultura", que seria um respeito ao ser humano orgânico e à pessoa, sem a essencialidade da cultura como elemento mediador dos processos de integração (CHRISTENSEN, 2012).

Em última instância, essas mudanças de denominações retratavam - e continuam a refletir - os dilemas das sociedades urbanas ante a acomodação das minorias étnico-raciais. Em consequência, ora a cultura é concebida como um recurso integrador das relações sociais e acomodação das minorias, ora como um instrumento de fragmentação das relações entre grupos sociais nos contextos urbanos. Com o intuito de contribuir para uma maior clareza do papel da cultura na identidade social do indivíduo, bem como das políticas afirmativas na acomodação das minorias, a terceira parte deste artigo aborda o debate do multiculturalismo no contexto do pensamento político contemporâneo, observando que a fundamentação teórica das políticas de identidade emergiu no cerne dessa discussão.

\section{OS DIREITOS DAS MINORIAS NAS SOCIEDADES DEMOCRÁTICAS}

São grandes as controvérsias que pairam sobre o termo "multiculturalismo", estando a causa maior ligada ao fato de que sua adoção pressupõe o reconhecimento oficial da diversidade. Conforme observam Gozdecka, Ercan e Kmak (2014, p. 53), mais do que caracterizar ou apontar para a composição demográfica de uma sociedade culturalmente plural, "[...] é sobre a adoção de uma ampla gama de políticas públicas, direitos legais e, em alguns casos, as disposições constitucionais para a acomodação das diferenças culturais que subjaz o princípio do multiculturalismo", sendo este o aspecto que o distingue da concepção de assimilação que geralmente permeia os modos pelos quais as diversidades étnicas e culturais são pensadas nas sociedades democráticas.

Outro aspecto importante e que muitas vezes passa despercebido refere-se às peculiaridades que tomam as políticas multiculturais em cada país, a depender das configurações multiculturais e demandas políticas, sociais e culturais internas dos grupos minoritários. Enquanto, de modo geral, para os imigrantes, as questões religiosas e a língua são as demandas mais recorrentes, e para os afro-americanos, a reconstituição e

Educação \& Formação, Fortaleza, v. 4, n. 10, p. 195-213, jan./abr. 2019 
registro de sua história e o reconhecimento de suas expressões culturais; já para as minorias nacionais (indígenas e outros povos que vivem em territórios ocupados), as reivindicações se centram nos direitos de autogoverno, ou seja, no direito de decidirem e legislarem sobre as normas e leis de sua própria comunidade (KYMLICKA, 2000),

A título de exemplo, Song (2014) lista um conjunto de políticas multiculturais que bem traduzem a diversidade dos pleitos entre os grupos minoritários, a saber: isenção do uso da regra geral para membros das minorias; assistência diferenciada aos membros das minorias quando da realização de algumas atividades (tradução de serviços para a língua materna, por exemplo); reconhecimento do código de algumas tradições culturais e religiosas acima da legislação jurídica civil; fundos para escolas bilíngues, associações étnicas, ações afirmativas; cotas em instituições governamentais, autogoverno, etc. De acordo com a autora, as políticas multiculturais compreendem tudo aquilo relacionado à concordância dos grupos culturalmente minoritários, decorrendo disso as grandes controvérsias que pairam em torno da legitimidade de suas demandas.

Em consequência, quando as políticas multiculturais são analisadas pelo ângulo das tensões sociais que marcam a crescente participação das minorias étnico-raciais nos contextos urbanos das sociedades democráticas ocidentais, duas posições teóricas podem ser identificadas. De um lado, encontram-se os discursos que procuram defender e fundamentar os direitos diferenciados das minorias como de igual valor e legitimidade se comparados aos direitos universais do indivíduo nas sociedades democráticas liberais. Para esse grupo, quando se trata da integração das minorias, é a cultura ou os grupos culturais que precisam ser reconhecidos e incluídos, ou devidamente acomodados, na sociedade dominante. Ainda que o conceito de cultura comporte uma imensa gama de interpretações e reivindicações, defende a valorização das identidades culturais desrespeitadas e a mudança no padrão dominante de representação e comunicação da sociedade como questão fundamental para a integração e a acomodação das minorias.

De outro lado, encontram-se os que se posicionam contra as políticas multiculturais, no sentido de não conceberem o reconhecimento e a valorização da cultura ou da identidade cultural como fator incondicional à acomodação das minorias nas grandes sociedades. Para esse grupo, à proporção que as minorias se apropriam e incorporam à cultura cosmopolita das sociedades urbanas, mais estarão aptas aos 
processos de inclusão social. Mais importante do que as políticas de identidade, de natureza simbólica, são as políticas de redistribuição e reestruturação econômica como mecanismo de inclusão e equidade social das minorias.

Um aprofundamento nos argumentos que explicam o embate entre essas duas posições possibilita a compreensão dos pressupostos teóricos que fundamentam as políticas multiculturais, bem como dos discursos mais recentes contra 0 multiculturalismo. Vale salientar que essas duas grandes abordagens aglutinam uma diversidade maior de interpretações e tendem a se diferenciar em função da gradação com que se posicionam a favor ou contra as políticas de identidades.

O ponto divisor das duas posições se situa na interpretação que cada grupo dá aos princípios liberais de liberdade e igualdade que fundamentam a constituição dos Estados-Nações modernos e continuam a guiar as sociedades democráticas contemporâneas. A característica definidora da doutrina liberal-democrática se assenta em dois direitos inalienáveis: a liberdade do indivíduo de discernir sobre a própria vida com base naquilo que julgue necessário e melhor para si, incluindo a possibilidade de reexame de suas escolhas; e o direito de ser tratado como igual, de acordo com os preceitos e normas jurídico-constitucionais de seu Estado. Considerando esses princípios, o fato de que nem sempre as pessoas façam boas escolhas em relação à própria vida não justifica a ideia de que estas venham a ser tomadas à revelia de sua vontade, pelo Estado, comunidade ou qualquer outra entidade política ou social (CALLAN, 1988; KYMLICKA, 2000; WINCH, 2002).

Dessa forma, haveria duas precondições no pensamento democrático para que 0 indivíduo tenha uma boa vida: primeiro, que conduza a própria vida com suporte em suas escolhas e em conformidade com suas crenças e valores, estando livre para questionar e reexaminar essas crenças e valores; segundo, que o indivíduo disponha dos recursos e liberdade necessários para discernir sobre suas escolhas, cabendo ao Estado assegurar esses recursos. Nesse caso, assegurar recursos implica tanto proteger as pessoas de arbítrios e barreiras externas quanto fornecer meios materiais, emocionais e intelectuais (opções, suporte, formação, conhecimentos) para que elas façam escolhas de modo livre e consciente (CALLAN, 1988; CHRISTMAN, 2014; WINCH, 2002). 
É nesse ponto, na forma como o Estado e a sociedade devem assegurar e dar suporte às escolhas dos indivíduos, que se encontra a diferença entre as duas perspectivas do pensamento liberal-democrático em relação às políticas multiculturais. Enquanto Kymlicka (2000) defende que não existem boas escolhas ausentes de contextos culturais, de filiação cultural, os liberais contrários às políticas multiculturais, aos direitos coletivos, ressaltam que a proteção às tradições e normas culturais de determinados grupos impedem a integração e acomodação adequada das minorias na cultura cosmopolita que caracteriza as sociedades democráticas urbanas, além de ir de encontro aos direitos inalienáveis do indivíduo ou coibi-los, isso se dando em função de vários fatores.

O primeiro fator vincula-se ao fato de o Estado, amparando os direitos diferenciados das minorias, não ter como proteger os membros dos próprios grupos minoritários de eventuais arbítrios decorrentes das tradições e normas culturais que regem as relações sociais internas. Em casos específicos, as tradições culturais tendem a perpetuar desigualdades e diferenças entre os membros de um mesmo grupo, isso ocorrendo sobretudo em relação aos direitos das mulheres (SONG, 2014). O segundo ponto está ligado ao hibridismo cultural subjacente às sociedades urbanas cosmopolitas como suporte mais rico para as escolhas dos indivíduos. Uma vez que os contextos cosmopolitas oferecem um universo mais abrangente de opções para os indivíduos em todas as esferas da vida social (educacional, cultural, profissional e política), estas disporiam de um ambiente mais adequado e satisfatório para realizar suas escolhas, o mesmo não se dando quando a referência da pessoa se restringe a uma única cultura.

Além de um conjunto mais amplo de opções, o fato de hoje vivermos em um mundo culturalmente híbrido torna difícil ou impossível a demarcação entre as culturas, de modo que estas não podem ser concebidas como algo distinto e puro (SONG, 2014). Finalmente a terceira crítica ao multiculturalismo se refere à diferença entre políticas de identidade (dirigidas a grupos culturais específicos) e políticas de redistribuição (pensadas para corrigir as desigualdades sociais de cunho estruturais, não necessariamente ligadas a problemas de filiação cultural). Para a maioria dos liberais, quando o Estado privilegia as políticas de identidade ou de reconhecimento, tende a enfraquecer as políticas de redistribuição e reestruturação econômica, representando as

Educação \& Formação, Fortaleza, v. 4, n. 10, p. 195-213, jan./abr. 2019 
primeiras o único caminho capaz de integrar as minorias no mainstream da grande sociedade (SONG, 2014).

$\mathrm{Na}$ perspectiva desse grupo, o racismo e o preconceito constituem os grandes obstáculos à adequada acomodação dos grupos étnico-raciais nos contextos urbanos e plurais das sociedades democráticas contemporâneas. À proporção que a sociedade busque superar esse comportamento em relação aos negros, imigrantes, índios e demais minorias e que as políticas de redistribuição e reestruturação econômica contribuam para amenizar as desigualdades sociais, os obstáculos ao processo de integração e acomodação desses grupos deixam de existir. Para esse grupo, o papel do Estado não é o de proteger grupos ou associações étnico-raciais, mas de garantir a civilidade e a integração social com base nos direitos inalienáveis das pessoas e no desenvolvimento de mecanismos de combate aos preconceitos e discriminações sociais.

Em seu livro Multicultural citizenship, Kymlicka (2000) tenta desconstruir esses argumentos e mostrar como os direitos diferenciados das minorias são absolutamente condizentes com os princípios de liberdade e igualdade que guiam as sociedades democrático-liberais. Para o autor, liberdade e autonomia são conceitos intimamente ligados e dependentes da cultura dos indivíduos. Conforme observa, todas as pessoas estão inseridas ou pertencem a uma cultura social, aquilo que thes fornece formas significativas de vida em toda gama das atividades humanas e sociais, incluindo a vida educacional, recreativa e econômica, que englobam tanto as esferas públicas como privadas da sociedade. As culturas sociais, nesse sentido, não se restringem ao compartilhamento de memórias e valores, mas envolvem o vocabulário e as práticas cotidianas da vida social, e elas de fato são o que oferecem suporte e significado às escolhas dos indivíduos.

Consoante Kymlicka (2000), as culturas sociais surgiram ligadas ao desenvolvimento das economias modernas de mercado, que, dada a natureza peculiar de sua dinâmica, exigiam elementos, como uma força de trabalho móvel, alfabetizada e guiada por um alto nível de solidariedade. Tudo isso envolvia a difusão em todas as instâncias da sociedade - economia, política e instituições educacionais - de valores, crenças, normas e ideais comuns, capazes de levar as pessoas a desenvolverem um forte sentimento de identidade nacional. Além de basear-se em uma língua comum, 
eram territorialmente concentradas, confluindo todos esses componentes para 0 florescimento dos Estados-Nações modernos.

Segundo Kymlicka (2000), é com base nessa dinâmica social e política, costurada pela ideia de uma identidade compartilhada dando forma e sustentação aos Estados-Nações, que muitos liberais hoje defendem a legitimidade cultural das sociedades urbanas democráticas, que, ao se imbuírem de uma aura cosmopolita, caleidoscópica, estariam acima e englobando o conjunto de aspectos e a diversidade de outras culturas. No entanto, conforme observa Kymlicka (2000), a percepção de que todos os países internamente compartilham uma cultura comum, baseada em língua única, não mais condiz com a realidade da maioria das nações. Assim, o autor procura desmistificar a ideia de que a modernização das sociedades ocidentais teria deslocado ou acabado com qualquer sentimento particular de identidade cultural.

Para ele, não existe procedência no argumento de que, uma vez inseridas em um contexto cosmopolita, as pessoas naturalmente se desenraizariam de sua cultura particular. Conforme ressalta Kymlicka (2000, p. 85), "[...] viver numa sociedade caleidoscópica não significa necessariamente mover-se entre culturas sociais, mas desfrutar de oportunidades fornecidas por uma cultura social mais diversa". O autor observa que o fato de um americano irlandês poder, entre outros deleites, desfrutar da culinária chinesa e ler para os filhos uma versão inglesa dos "Contos de Grimm" (a famosa coletânea de histórias infantis dos irmãos alemães Jacob e Wilhelm Grimm) não significa que ele se tornou um indivíduo desarraigado de valores culturais que lhe são próprios.

Para Kymlicka (2000), esse americano certamente tem igual apego ao seu "estilo de vida" ou aos valores de sua cultura "caleidoscópica" tanto quanto tem qualquer outro indivíduo pelas características e valores de sua cultura social específica, ainda que as intensidades de pertença cultural variem entre pessoas e grupos, a depender da conjuntura dos fatores que envolvam a vida social. Para o autor, são poucos os casos genuinamente de troca de culturas, sobretudo quando as diferenças na organização social e no desenvolvimento tecnológico das sociedades se mostram cada dia mais acentuadas. Conforme observa, há uma diferença substancial entre os processos de imigração e integração de pessoas que deixam seu país para viver em sociedades cujos

Educação \& Formação, Fortaleza, v. 4, n. 10, p. 195-213, jan./abr. 2019 
status econômico e social se assemelham ao seu contexto social de origem e aquelas que se movem em busca de uma realidade econômica e social mais próspera e estável.

Kymlicka (2000) ressalta que todo processo de integração representa uma via de mão dupla, requerendo uma adaptação recíproca entre a sociedade e o imigrante. Ao argumentar sobre os mecanismos apropriados ao processo de integração das minorias, o autor cita algumas prerrogativas. Primeiro, esse processo exige intenso esforço de combate ao preconceito e às discriminações sociais, envolvendo não apenas a aplicação de leis antidiscriminatórias, como mudanças na forma como as minorias são retratadas nos livros didáticos, nos documentos governamentais e na mídia. Segundo, o processo pressupõe mudanças também nas instituições da cultura dominante, de modo a permitir que alguns componentes importantes de outras culturas sejam apropriados, a exemplo dos feriados e datas comemorativas na tradição de outros grupos.

Outro aspecto seria reverter a percepção de que os imigrantes deveriam ser levados a abandonar a sua língua materna, quando o mais adequado seria incentivá-los a se tornarem bilíngues. Além de a língua materna ser o mecanismo básico de preservação de uma cultura e identidade, a negação à sua manifestação assume um forte teor racista, pois há uma tendência de se associar o aprendizado da língua dominante na sociedade, a exemplo do inglês, a uma condição de erudição, status econômico e social, enquanto se manter, nesse caso, sem 0 inglês implica desvantagem, pobreza, baixa realização e mesmo deslealdade.

Kymlicka (2000) entende que, ao contrário do que frequentemente propagam muitos liberais avessos às políticas multiculturais, a institucionalização das culturas sociais dos grupos minoritários não representa formas de recriação de culturas separadas e uma ameaça à integridade social de um país. Ao contrário, o respeito à cultura e à identidade das minorias tende a contribuir para uma maior integração destas aos padrões sociais vigentes, sem esquecer o fato de que a acomodação da diversidade amplia e enriquece as opções e perspectivas das culturas dominantes.

Por fim, o autor observa que, embora os Estados Unidos, desde os anos 1970, reconheçam-se como nação multicultural, no sentido de rejeitar o antigo modelo de assimilação e adotar uma política de maior tolerância e pluralismo, permitindo e mesmo encorajando as manifestações de vários aspectos e eventos de herança étnica (comidas, vestimentas, religiões, associações comunitárias e culturais, entre outros), ainda se 
posicionam de modo bastante ambíguo em relação aos direitos civis das minorias. As concessões feitas às manifestações culturais não têm como foco a preservação das diferenças culturais como algo possível e valoroso para o país, funcionando como uma espécie de mecanismo mais adequado à integração dos imigrantes e negros na cultura dominante.

Nesse caso, supõe-se que a preocupação dos Estados Unidos e demais nações desenvolvidas com o multiculturalismo ou a polietnicidade representa antes uma estratégia de integração das minorias nas culturas dominantes do que um compromisso real com os valores e crenças das diferentes culturas sociais.

\section{CONSIDERAÇÕES FINAIS}

Este artigo inicia com a problemática do negro dentro de uma sociedade predominantemente branca e historicamente marcada por conflitos raciais. Mostra 0 protagonismo do movimento negro na conquista de espaços e direitos sociais e culturais, em um período cujos conflitos étnico-raciais se restringiam à acomodação das minorias clássicas - negros, população nativa, alguns grupos de imigrantes - na sociedade dominante. Aos poucos, esses conflitos se ampliam e passam a retratar a gama da diversidade étnica, racial, cultural, social e de gênero que pauta as relações de convivência entre os grupos nas grandes sociedades urbanas. Como consequência, ao lado dos movimentos em defesa da diversidade e das políticas de identidade, assiste-se mundo afora à emergência de ideologias e movimentos conservadores que resistem às demandas por mudanças sociais, econômicas, políticas e culturalmente inclusivas, entendidas como inevitáveis.

Diante desse cenário, o que o debate sobre o multiculturalismo e a educação multicultural tem a nos dizer? Primeiro, que o multiculturalismo continua sendo uma das questões mais centrais e controversas das sociedades e estados contemporâneos e, como tal, as discussões sobre a legitimidade de suas políticas não mais se circunscrevem aos grupos minoritários. Segundo, que, para se efetivar como nação multicultural, um país precisa institucionalizar as várias culturas sociais que existem ao lado da cultura dominante. Isso implica o estabelecimento de um conjunto de instituições sociais, educacionais e econômicas e de políticas de suporte às minorias. 
Dentro desse quadro, é possível afirmar que o movimento da educação multicultural nos Estados Unidos continua desempenhando um papel primordial não apenas nos processos de inclusão escolar das minorias, como na luta, em geral, pelos direitos das culturas sociais. Desde os anos de 1990, os defensores desse movimento:

- abandonaram uma concepção limitada e ingênua de educação multicultural centrada quase exclusivamente na inserção de conteúdos multiculturais no currículo escolar para a compreensão de que uma educação inclusiva pressupõe um posicionamento político, teórico e ideológico dos educadores ante os índices pouco promissores de aprendizagem dos alunos vindos das minorias étnico-raciais;

- entenderam politicamente que a função primeira da escola pública é efetivamente capacitar seus alunos (em grande parte oriundos das minorias étnico-raciais) para que desenvolvam reais processos de aprendizagem e, dessa forma, possam se inserir nos espaços legítimos da grande sociedade;

- compreenderam teoricamente que não há ensino e aprendizagem ausentes de padrões culturais e que a negação da identidade cultural das minorias étnico-raciais (sua história, língua, valores, crenças, entre outros) no contexto escolar compromete a performance de grande parte de seus alunos;

- rejeitaram qualquer pressuposto ou tendência de atrelar falta de aprendizagem a condições sociais e culturais específicas;

- acreditaram ideologicamente no valor da educação como instrumento de transformação das relações sociais na escola e na sociedade.

Os defensores do movimento da educação multicultural percebem todas essas dimensões como parte de um projeto de educação e escola, embora compreendam que, na realidade cotidiana de sua prática, são muitos os obstáculos e dificuldades a serem trabalhados e vencidos. O que resta claro, todavia, para esse grupo, é o valor da educação multicultural como abordagem que se posiciona acima de um discurso meramente retórico de respeito às identidades étnico-culturais, estando hoje comprometidos com uma proposta de mudança substancial no padrão cultural tradicional e dominante de formação escolar. Para eles, é inadmissível que um país como os Estados Unidos, com tamanha diversidade étnica e cultural, permaneça fincado em um 
modelo único de formação acadêmica, fundamentado na história, cultura e valores anglo-saxônicos da população branca americana.

Isso passa pela compreensão de que multiculturalismo não é mais uma pauta apenas de minorias, mas diz respeito à grande sociedade. Somos todos sujeitos culturais em um mundo imensamente diversificado, multicultural, não mais cabendo a prevalência, sobretudo na escola, de valores e comportamentos incompatíveis com a configuração étnica, racial e cultural da grande sociedade.

\section{REFERÊNCIAS}

BANKS, J. A. An introduction to multicultural education. 2. ed. Massachusetts: Allyn and Bacon, 1999.

BANKS, J. A. Multicultural education: historical development, dimensions and practice. American Educational Research Association, Washington, DC, v. 19, p. 3-49, 1993.

CALLAN, E. Autonomy and schooling. Quebec: McGill-Queen's University, 1988.

CARTER, I. Positive and negative liberty. Stanford Encyclopedia of Philosophy. 2012. Disponível em: <https://plato.stanford.edu/archives/spr2012/entries/liberty-positive-negative/>. Acesso em: 10 jan. 2015.

CHRISTENSEN, E. Revisiting multiculturalism and its critics. The Monist, Manchester, v. 95, n. 1, p. 33-48, 2012.

CHRISTMAN, J. Autonomy in moral and political philosophy. Stanford Encyclopedia of Philosophy. 2014. Disponível em: <https://plato.stanford.edu/archives/win2014/entries/ autonomy-moral/>. Acesso em: 16 dez. 2014.

FULLINWIDER, R. Affirmative action. Stanford Encyclopedia of Philosophy. 2014. Disponível em: <http://plato.stanford.edu/archives/win2014/entries/affirmative-action/>. Acesso em: 17 mar. 2015.

GOZDECKA, D. A.; ERCAN, S. A.; KMAK, M. From multiculturalism to postmulticulturalism: trends and paradoxes. Journal of Sociology, London, v. 50, n. 1, p. 5164, 2014.

KYMLICKA, W. Multicultural citizenship. 4. ed. New York: Oxford University, 2000.

LEYDET, D. Citizenship. Stanford Encyclopedia of Philosophy. 2014. Disponível em: <http://plato.stanford.edu/archives/spr2014/entries/citizenship/>. Acesso em: 11 mar. 2015. 
SONG, S. Multiculturalism. Stanford Encyclopedia of Philosophy. 2014. Disponível em: <http://plato.stanford.edu/archives/spr2014/entries/multiculturalism/>. Acesso em: $12 \mathrm{dez}$. 2014.

SOUTO-MANNING, M. Freire, teaching, and learning: culture circles across contexts. New York: Peter Lang, 2010.

SOUTO-MANNING, M. Multicultural teaching in the early childhood classroom: approaches, strategies, and tools preschool-2nd grade. New York: Columbia University, 2013.

TAYLOR, C. Interculturalism or multiculturalism? Philosophy and Social Criticism, London, v. 38, n. 4-5, p. 413-423, 2012.

WINCH, C. Strong autonomy and education. Educational Theory, Illinois, v. 52, n. 1, p. 27-41, 2002.

WOODSON, C. G. Mis-Education of the Negro. Washington, DC: Associated Publishers, 1969.

Mônica Farias Abu-El-Haj (Brasil, Ceará, Fortaleza) - Universidade Estadual do Ceará (UECE)

Pós-Doutora em Educação pela Universidade de Columbia. Professora do Centro de Educação da UECE.

Lattes: <http://lattes.cnpq.br/3072807381390748>.

E-mail: <monicaffarias@gmail.com>.

Recebido em 30 de setembro de 2017.

Aceito em 12 de janeiro de 2018. 